\title{
Synthesis and characterization of the photochromic properties of new pyrrolidene dyes bearing benzothiazole or benzothiazolium acceptor groups
}

\author{
M. Cidália R. Castro ${ }^{\mathrm{a}}$, Paulo J. Coelho ${ }^{\mathrm{b}}$ and M. Manuela M. Raposo ${ }^{\mathrm{a}}$ \\ ${ }^{a}$ Centro de Química, Universidade do Minho, Campus de Gualtar, 4710-057 Braga, \\ Portugal. \\ email: mfox@quimica.uminho.pt \\ ${ }^{b}$ Centro de Química-Vila Real, Universidade de Trás-os-Montes e Alto Douro, 5001 - \\ 801 Vila Real, Portugal.
}

\begin{abstract}
A series of novel pyrrolidene imines and an ethene derivative bearing functionalized benzothiazole or benzothiazolium acceptor groups were synthesized, characterized and their photochromic properties, at room temperature, evaluated using the photostationary technique. While the imines did not show significant photochromic properties, visible irradiation of the diarylethene derivative led to a fast trans-cis isomerization of the $\mathrm{C}=\mathrm{C}$ bond, with the concomitant change in the absorption spectrum. The cis isomer is not thermally stable and, in the absence of light, reisomerizes slowly back to the trans form.
\end{abstract}

Keywords: Pyrrole, Benzothiazole, Schiff bases; Benzothiazolium ethene dye, Photochromism; Molecular switches. 


\section{Introduction}

Schiff bases are an important class of compounds with a variety of applications in medicine, materials and supramolecular chemistry due to their biological (anticancer, antimalaria, antivirus, antimicrobial, etc.) and optical properties (chemosensors, and nonlinear optical) [1]. Additionally they can be used as ligands, able to complex with different metals in various oxidation states, controlling their performance in useful catalytic transformations [2].

The reversible photoinduced trans-cis isomerization of stilbenes and Schiff base derivatives has been comprehensively studied in the last decades, either in solution or in the solid state [3]. UV or visible irradiation of the thermodynamically more stable transisomer produces the cis-isomer that returns to the initial form either thermally of through irradiation with light of a different wavelength (Scheme 1).

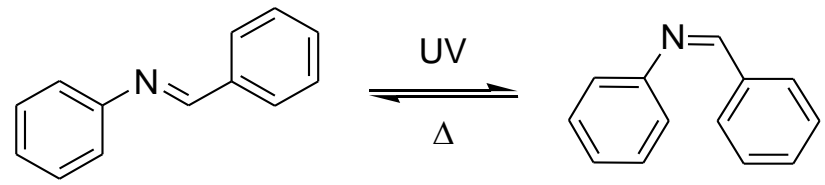

Scheme 1. Photochemical and thermal isomerization of benzylidene aniline-type imines.

Earlier, it was reported that, the introduction of electron donor/acceptor groups in the aromatic rings of the $\mathrm{N}$-benzylidene anilines led to some tailoring of the photoresponse. Nevertheless, the photoisomerization could only be detected at low temperature $\left(-25^{\circ}\right.$ to $\left.-10^{\circ}\right)[4]$.

More recently, we have showed that the kinetic rate of the thermal cis-trans reisomerization of pyrrolidene Schiff bases, at room temperature, can be controlled through proper substitution at the aniline ring of the molecule [5]. Having in mind theses results and as part of an on-going research to develop efficient heterocyclic systems for photochromic applications [6] we decided to prepare some simple heterocyclic imines $\mathbf{1}$ and the corresponding vinyl derivative $\mathbf{2}$ functionalized with benzothiazole or benzothiazolium acceptors groups linked to the pyrrole ring through position 2 or 6 of the benzothiazole ring in order to evaluated their photochromic properties by UV spectroscopy. 


\section{Experimental}

\subsection{Synthesis}

General procedure for the synthesis of imines 1: a solution of 2-formylpyrrole (2 $\mathrm{mmol})$, aminobenzothiazole (2 mmol), acetic acid (2 drops) in ethanol (15 mL) was heated at reflux and monitored by TLC, which determined the reaction time (9-24 h). After cooling and solvent evaporation, the crude product was recrystallized from light petroleum/dichloromethane or ethanol to afford the pure imines $\mathbf{1}$.

Presentation of the characterization of compound $\mathbf{1 b}$ as an example:

$N$-((1H-pyrrol-2'-yl)methylene)benzo[d] thiazol-2-amine (1b). Brown solid (16\%). Mp 164-166 'C. ${ }^{1} \mathrm{H}$ NMR (DMSO-d 6 ) $\delta$ 6.33-6.36 (m, 1H, 4'-H), 7.09 (dd, 1H, J=3.6 and $\left.\mathrm{J}=2.1 \mathrm{~Hz}, 3^{\prime}-\mathrm{H}\right), 7.28-7.29\left(\mathrm{~m}, 1 \mathrm{H}, 5^{\prime}-\mathrm{H}\right), 7.35$ (dt, $1 \mathrm{H}, J=6.3$ and $\left.J=1.2 \mathrm{~Hz}, 5-\mathrm{H}\right)$, $7.45(\mathrm{dt}, 1 \mathrm{H}, J=6.3$ and $J=1.2 \mathrm{~Hz}, 6-\mathrm{H}), 7.82(\mathrm{dd}, 1 \mathrm{H}, J=6.6$ and $J=1.3 \mathrm{~Hz}, 4-\mathrm{H}), 7.98$ (dd, $1 \mathrm{H}, J=6.6$ and $J=1.3 \mathrm{~Hz}, 7-\mathrm{H}), 8.86(\mathrm{~s}, 1 \mathrm{H}, \mathrm{CHN}), 12.28(\mathrm{br} \mathrm{s}, 1 \mathrm{H}, \mathrm{NH}) .{ }^{13} \mathrm{C} \mathrm{NMR}$ $\left(\mathrm{DMSO}_{-} \mathrm{d}_{6}\right) \delta 111.6,121.8,122.1,124.5,126.4,128.2,129.6,133.6,151.6,154.9$, 172.5. IR (Nujol): v 2725, 2671, 1606, 1534, 1306, $1248 \mathrm{~cm}^{-1}$. Elemental Analysis for $\mathrm{C}_{12} \mathrm{H}_{9} \mathrm{~N}_{3} \mathrm{~S}$ : Found: $\mathrm{C}, 62.95 ; \mathrm{H}, 4.16 ; \mathrm{N}, 18.35 ; \mathrm{S}, 14.42 \%$ CHNS requires: C, 63.41; H, $3.99 ; \mathrm{N}, 18.49 ; \mathrm{S}, 14.11$.

Synthesis of compound 2: a solution of 2-formylpyrrole (1 mmol), methylbenzothiazolium salt $(1 \mathrm{mmol})$ and piperidine $(2$ drops $)$ in methanol $(10 \mathrm{ml})$ was heated at reflux for about 6 hours. After this time the precipitated was filtered and washed with ethanol to give the pure product 2.

2-((E)-2-(1-methyl-1H-pyrrol-2'-yl)vinyl)-3-methylbenzothiazolium iodide (2).

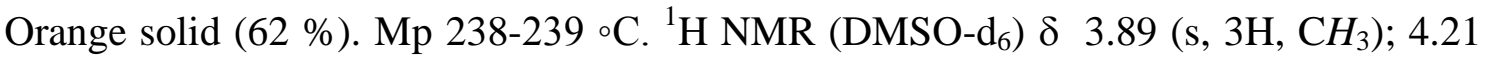
(s, 3H, N ${ }^{+} \mathrm{CH}_{3}$ ); 6.37-6.39 (m, 1H, 4'-H), 7.37-7.38 (m, 1H, 3'-H), 7.45 (dd, 1H, J = 4.2 and $\left.\mathrm{J}=1.5 \mathrm{~Hz}, 5^{\prime}-\mathrm{H}\right) 7.51\left(\mathrm{~d}, 1 \mathrm{H}, J=15.2 \mathrm{~Hz}, \mathrm{C}=\mathrm{CH}_{\beta}\right), 7.67(\mathrm{dt}, 1 \mathrm{H}, J=7.7$ and $J=1.1$ $\mathrm{Hz}, 6-\mathrm{H}), 7.78(\mathrm{dt}, 1 \mathrm{H}, J=7.7$ and $J=1.1 \mathrm{~Hz}, 5-\mathrm{H}), 7.95\left(\mathrm{~d}, 1 \mathrm{H}, J=15.2 \mathrm{~Hz}, \mathrm{C}=\mathrm{CH} H_{\alpha}\right.$ ), 8.08-8.11 (m, $1 \mathrm{H}, 7-\mathrm{H}), 8.30(\mathrm{dd}, 1 \mathrm{H}, J=8.1$ and $J=0.9 \mathrm{~Hz}, 4-\mathrm{H}) .{ }^{13} \mathrm{C}$ NMR (DMSO-d 6 ) $\delta 34.1,35.6,106.1,111.7,115.9,118.0,123.8,126.8,127.5,128.9,130.4,132.9,136.5$, 141.9, 171.0. IR (Nujol): v 1601, 1528, 1302, 1237, 1152, 1064, $1020 \mathrm{~cm}^{-1}$. Elemental Analysis for $\mathrm{C}_{15} \mathrm{H}_{15} \mathrm{IN}_{2} \mathrm{~S}$ : Found: C, 47.39; H, 3.92; N, 7.44; S, 8.17. \% CHNS requires: C, 47.13; H, 3.96; N, 7.33; S, 8.39. 


\subsection{Photochromic measurements}

UV irradiation experiments were made using a UV-vis Cary 50 Varian spectrometer coupled to a $150 \mathrm{~W}$ ozone free Xenon lamp. The light from the UV lamp was filtered using a water filter and a long-pass filter (Schott $>420 \mathrm{~nm}$ ) and then carried to the spectrophotometer holder perpendicularly to the monitoring beam using an optical fiber system. The light flux power (without the visible filter) $40 \mathrm{~W} \mathrm{~m}^{-2}$, was measured with a Photometer with UV-A probe. A temperature controlled $\left(20^{\circ} \mathrm{C}\right) 10 \mathrm{~mm}$ quartz cell $(3.5$ $\mathrm{mL}$ of sample solution) equipped with magnetic stirring was used. The maximum absorption wavelength of the stable trans form of the compounds was determined and then the absorbance was measured at $\lambda_{\max }$ while performing Vis light irradiation/dark cycles.

\section{Results and discussion}

\subsection{Synthesis}

Imines 1 were synthesized through Schiff-base condensation of commercial available 2formyl-pyrrole with amino-benzothiazole derivatives, in ethanol at room temperature (Scheme 1). Purification of the crude products by recrystallization gave the pure compounds in moderate to good yields (9-61\%).

Benzothiazolium salt 2 was synthesized through condensation of the precursor 2formyl-1-methylpyrrole with 1-methylbenzothiazolium salt in methanol at reflux, in the presence of a catalytic amount of piperidine for about 5 hours. After this time the precipitated was filtered and washed with ethanol to give the pure product $\mathbf{2}$.

All compounds were characterized by ${ }^{1} \mathrm{H}$ and ${ }^{13} \mathrm{C}$ NMR, IR, and EA and the data obtained are in full agreement with the proposed formulation. The most characteristic

signals in the ${ }^{1} \mathrm{H}$ NMR spectra of this family of Schiff bases were those corresponding to the $\mathrm{NH}$ of the pyrrole heterocycle and the $\mathrm{CH}=\mathrm{N}$ protons. For example, for compounds 1a-c the $\mathrm{CH}=\mathrm{N}$ protons resonate at $8.39-8.86 \mathrm{ppm}$, whereas pyrrole $\mathrm{NH}$ protons were found in the 11.80-12.28 ppm interval. On the other hand compound 2 exhibit two doublets at 7.51 and $7.95 \mathrm{ppm}$ with coupling constants of $15.2 \mathrm{~Hz}$ indicating a trans configuration of the vinylic protons. 
Table 1. Yields and maximum wavelength of absorption $\left(\lambda_{\max }\right)$ for compounds $\mathbf{1 - 2}$ in acetonitrile.

\begin{tabular}{cccc}
\hline Comp. & Yield (\%) & Reaction time (hrs) & $\lambda_{\max }(\mathrm{nm})$ \\
\hline 1a & 4 & 24 & $334,431(\mathrm{w})$ \\
1b & 16 & 22 & 369 \\
1c & 59 & 9 & 380 \\
2 & 62 & 6 & 466 \\
\hline
\end{tabular}

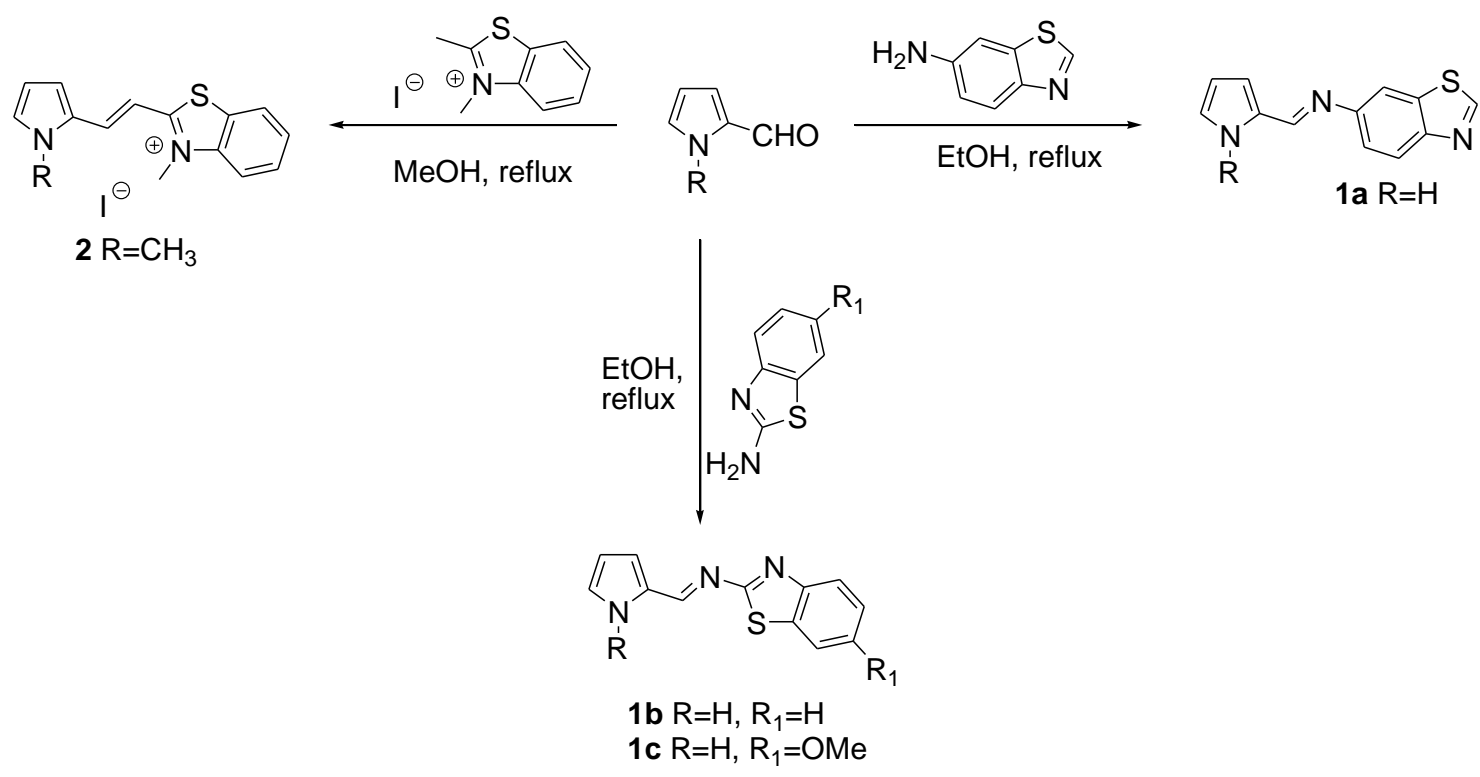

Scheme 2. Synthesis of pyrrolidene imines 1-2.

\subsection{Trans-cis photochemical isomerization}

In acetonitrile solution 1a-c present a broad absorption band in the UV region with $\lambda_{\max }$ between 334 and $380 \mathrm{~nm}$. Compound 1a exhibit also a second low intensity band at $431 \mathrm{~nm}$. Diarylethene 2 present an intense absorption band in the visible region and therefore their acetonitrile solutions are intensively coloured (orange).

The trans-cis isomerization of the $\mathrm{C}=\mathrm{C}$ or $\mathrm{C}=\mathrm{N}$ double bond can usually be achieved by UV-Vis irradiation which leads frequently to the lowering of the absorption at $\lambda_{\max }$ since the cis isomer has a lower extinction coefficient. However, the UV-Visible 
irradiation of imines 1a-c, for several minutes, did not produce any significant changes in the UV-Vis spectra. This fact does not mean necessarily that the isomerization did not occurred, but probably that the switching between the two species takes place too quickly to be detected by this technique.

On the contrary, visible irradiation of compound $\mathbf{2}$ led to a very fast and significant decrease in the absorption al $\lambda_{\max }$ reaching a photostationary equilibrium in 20 seconds which is consistent with the light promoted trans-cis isomerization of the double bond (Scheme 3). When the light source was closed the absorbance of the solution increased slowly, due to the thermal cis-trans back isomerization, following a mono-exponential process with a rate constant of $\mathrm{K}=0.1834 \mathrm{Min}^{-1}$ which indicates that the cis-isomer has a lifetime of $3.8 \mathrm{~min}$ at room temperature. From the decay of the absorbance, one can estimate that the photostationary equilibrium is constituted by more than $38 \%$ of the cis isomer. The full return of the cis isomer to the trans form is therefore slow and takes about $20 \mathrm{~min}$. The phenomena could be reproduced several times demonstrating that no competitive reactions, leading to degradation products, are occurring.

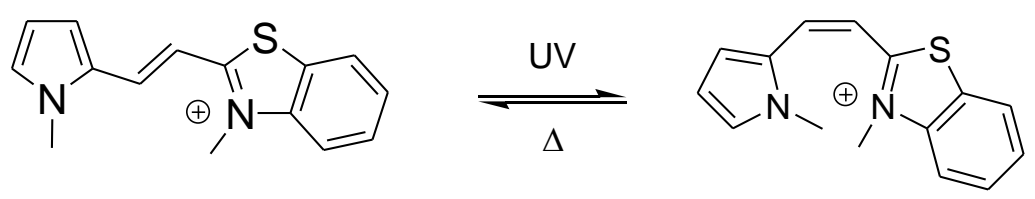

Scheme 3. Photochemical and thermal isomerization of diarylethene 2.

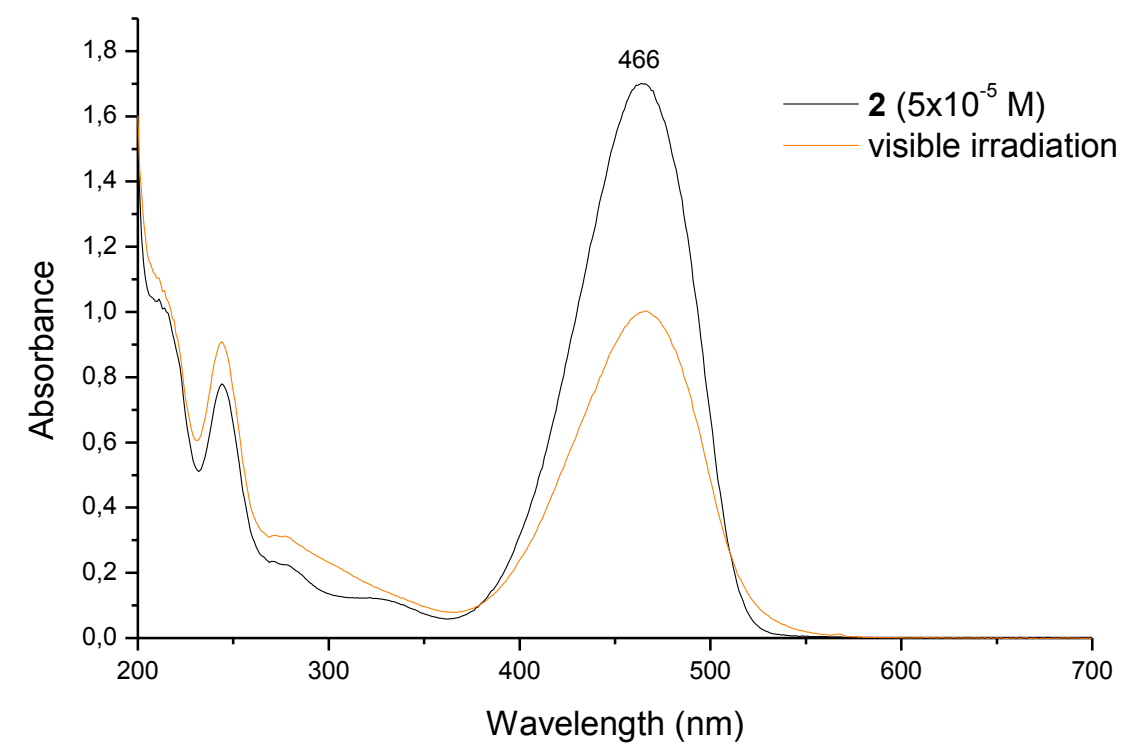


Figure 2. Absorption spectra of compound 2 in acetonitrile $\left(5 \times 10^{-5} \mathrm{M}\right)$ before and after visible irradiation.

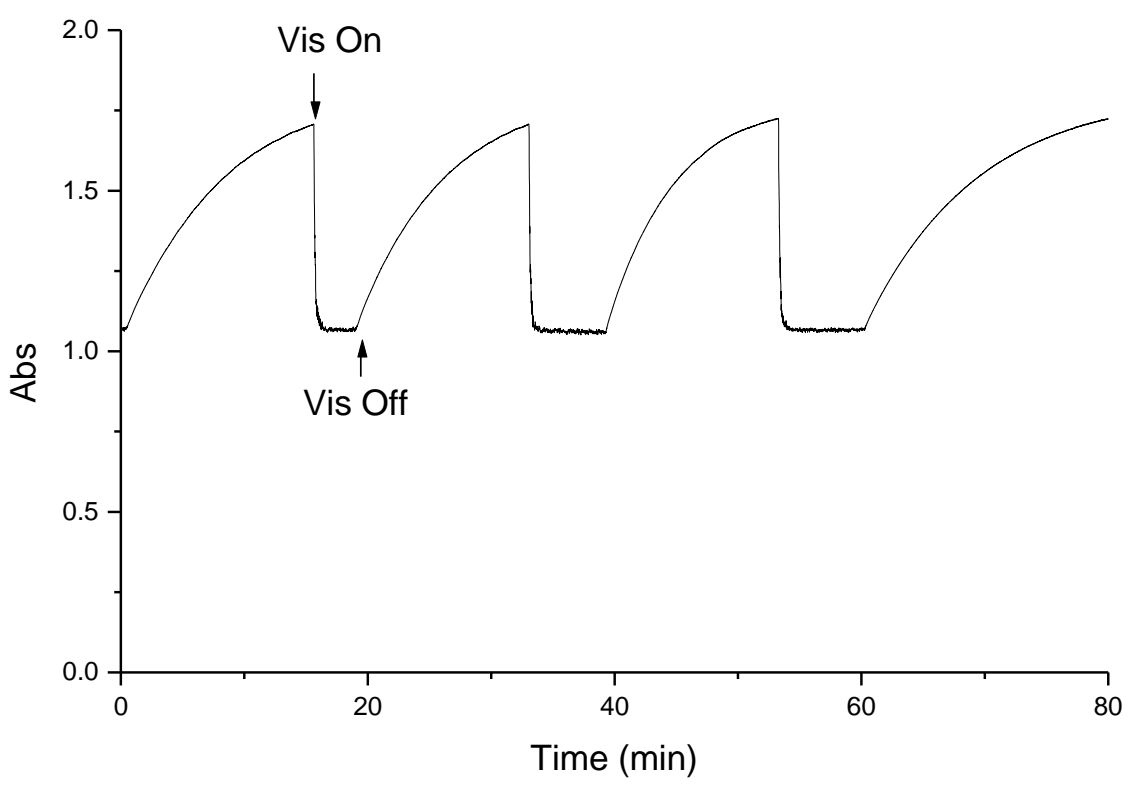

Figure 3. Photochemical and thermal isomerization of diarylethene 2 at $466 \mathrm{~nm}$.

\section{Conclusions}

New heterocyclic imines functionalized with benzothiazole or benzothiazolium acceptors groups linked to the pyrrole ring through position 2 or 6 of the benzothiazole ring and a new diarylethene derivative 2 with the same pattern were synthesized using simple experimental procedures. The ethene $\mathbf{2}$ showed photochromic properties and the switching between the trans and cis isomers could be performed, at room temperature, through exposure of acetonitrile solutions to visible light $(20 \mathrm{~s})$ followed by dark (20 $\min )$.

\section{Acknowledgements}

Thanks are due to the Fundação para a Ciência e Tecnologia (Portugal) and FEDERCOMPETE for financial support through the research units Centro de Química Universidade do Minho Project PEst-C/QUI/UI0686/2011 (FCOMP-01-0124-FEDER022716) and a PhD grant to M. C. R. Castro (SFRH/BD/78037/2011). The NMR spectrometer Bruker Avance III 400 is part of the National NMR Network and was 
purchased within the framework of the National program for Scientific Requipment, contract REDE/1517/RMN/2005 with funds from POCI 2010 (FEDER) and FCT.

\section{References}

[1] a) Przybylski, P.; Huczynski, A.; Pyta, K.; Brzezinski, B.; Bartl, F. Curr. Org. Chem. 2009, 13, 123. b) Yang, M.; Xu, D.; Xi, W.; Wang, L.; Zheng, J.; Huang, J.; Zhang, J.; Zhou, H.; Wu, J.; Tian, Y. J. Org. Chem. 2013, 78, 10344. c) Bhuiyan, M. D. H.; Teshome, A.; Gainsford, G. J.; Ashraf, M.; Clays, K.; Asselberghs, I.; Kay, A. J. Opt. Mater. 2010, 32, 669.

[2] Che, C. M.; Huang, J. S. Coord. Chem. Rev. 2003, 242, 97.

[3] a) Ziolek, M.; Burdzinski, G.; Filipczak, K.; Karolczak, J.; Maciejewski, A. Phys. Chem. Chem. Phys. 2008, 10, 1304. b) Zhao, L. Y.; Hou, Q. F.; Sui, D.; Wang, Y.; Jiang, S. M. Spectroc. Acta A 2007, 67, 1120. c) Ziolek, M.; Filipczak, K.; Maciejewski, A. Chem. Phys. Lett. 2008, 464, 181. d) Wang, Q. H.; Cai, L. Z.; Gao, F.; Zhou, Q. R.; Zhan, F. P.; Wang, Q. X. J. Mol. Struct. 2010, 977, 274. e) Fukuda, H.; Amimoto, K.; Koyama, H.; Kawato, T. Org. Biomol. Chem. 2003, 1, 1578. f) Hadjoudis, E.; Mavridis, I. M. Chem. Soc. Rev. 2004, 33, 579. g) Minkin, V. I.; Tsukanov, A. V.; Dubonosov, A. D.; Bren, V. A. J. Mol. Struct. 2011, 998, 179. h) J. S. Yang, K. L. Liau, C. Y. Hwang, C. M. Wang, J. Phys. Chem. A 2006, 110, 8003.

[4] King, N. R.; Whale, E. A.; Davis, F. J.; Gilbert, A.; Mitchell, G. R.; J. Mater. Chem. 1997, 7, 625 .

[5] Coelho, P.; Castro, M. C. R.; Raposo M. M. M. J. Photochem. Photobiol. Chem. A 2013, 259, 59 .

[6] a) Coelho, P.; Sousa, C. M.; Castro, M. C. R.; Fonseca, A. M. C.; Raposo M. M. M. Opt. Mater. 2013, 35, 1167. b) Coelho, P. J.; Castro, M. C. R.; Fonseca, A. M. C.; Raposo, M. M. M. Dyes and Pigments 2012, 92, 745. c) Coelho, P. J.; Castro, M. C. R.; Fernandes, S. S. M.; Fonseca, A. M. C.; Raposo, M. M. M. Tetrahedron Lett. 2012, 53, 4502. d) Raposo, M. M. M.; Fonseca, A. M. C.; Castro, M. C. R.; Belsley, M.; Cardoso, M. F. S.; Carvalho, L. M.; Coelho, P. J. Dyes and Pigments 2011, 91, 62. 